\title{
A PRÁTICA E A TEORIA NA INICIAÇÃO À DOCÊNCIA EM MATEMÁTICA
}

| | | | | | | | | | | | | | | | | | | | | | | | | | | | | | | | | | | | | | | | | | | | | | | | | | | | | | | | | | | | | | | | | | | | | | | | | | | | | | | | | | | | | | | | | | | | | | | | | | | | | | | | | | | | | | | | | | | | | | | | | | | | | | | | | | |

\author{
Pedro Augusto Pereira Borges ${ }^{1}$ \\ Milton Kist ${ }^{2}$
}

\begin{abstract}
RESUMO
Os cursos de Licenciatura em Matemática no Brasil tendem a reproduzir um modelo tecnicista com saberes desconectados das práticas escolares. O Programa Institucional de Bolsa de Iniciação à Docência (PIBID) apresenta-se como uma alternativa promissora de formação de professores, na medida em que tem na base de sua proposta a aproximação das licenciaturas com a Educação Básica. No PIBID Matemática na Universidade Federal da Fronteira Sul (UFFS) coloca-se o desafio de iniciar à docência, alunos em uma fase do curso, com poucos conhecimentos de Matemática, de teorias de aprendizagem e de Didática. No presente trabalho, são descritas e analisadas atividades de estudo bibliográfico, planejamento e apresentação de microaulas. Leitu-
\end{abstract}

1 Pós-Doutor em Educação Científica e Tecnológica, doutor em Engenharia Mecânica. Professor associado da Universidade Federal da Fronteira Sul (UFFS), coordenador de área do Subprojeto de Matemática (Campus Chapecó/ SC) do PIBID-UFFS. Contato: pedro.borges@uffs.edu.br

2 Doutor em Engenharia Mecânica e de Materiais. Professor adjunto da Universidade Federal da Fronteira Sul (UFFS), colaborador do Subprojeto de Matemática (Campus Chapecó/SC) do PIBID-UFFS. Contato: milton.kist@uffs.edu.br 
ras iniciais sobre a natureza do conhecimento matemático foram necessárias para compreender o que é a Matemática, como é feita, quem pode fazê-la e sua importância para a sociedade atual, assim como os processos indutivos inerentes à criação de proposições e os dedutivos próprios das demonstrações. A metodologia de trabalho do núcleo é de leituras individuais, complementadas pela discussão da teoria e relacionamento desta com elementos da prática pedagógica, como conteúdos escolares, estratégias de ensino, procedimentos didáticos e condições de trabalho. A elaboração cooperativa dos saberes experienciais, o ambiente cultural desenvolvido pelo núcleo nessas primeiras vivências e a necessária unidade entre prática e teoria foram apontados como os principais ganhos no processo de construção da identidade do professor.

Palavras-chave: Formação de professores. PIBID. Teoria e Prática. Didática da Matemática.

\section{INTRODUÇÃO}

A formação do professor de Matemática nos cursos de licenciatura poderia ser descrita (com evidente inspiração em Tardif (2008, p. 36-40), como um somatório de saberes, estruturados como componentes curriculares de várias áreas: os saberes disciplinares (saberes científicos específicos, produzidos pela comunidade de matemática e saberes matemáticos escolares); os saberes profissionais (saberes das ciências humanas que servem de base para a educação, como a Filosofia, a Psicologia e a Sociologia); os saberes curriculares (resultantes dos saberes disciplinares e profissionais, que geram as estratégias e os métodos de ensino); e os saberes experienciais (desenvolvidos nos estágios e na prática docente escolar). Enquanto os saberes disciplinares, os profissionais e os curriculares são produzidos no âmbito universitário, como pesquisa (conceitual e metodológica) voltada para a própria universidade, os saberes experienciais são produzidos pelos professores sobre sua própria prática pedagógica nas escolas. 
Está implícito, em geral, nos Projetos Pedagógicos dos Cursos de Matemática (PPCs) que esses quatro grupos de saberes sejam aplicados para o planejamento e a execução da prática de ensino, porém, devido ao isolamento existente entre eles, salvo elogiáveis exceções, não é o que ocorre. Para Pimenta, os cursos de formação

[...] ao desenvolverem um currículo formal com conteúdos e atividades de estágios distanciados da realidade das escolas, numa perspectiva burocrática e cartorial que não dá conta de captar as contradições presentes na prática social de educar, pouco têm contribuído para gestar uma nova identidade profissional docente. (PIMENTA, 1999, p. 16).

O currículo formal segue uma linha tecnicista de formação, como uma produção industrial, em que cada disciplina faz uma parte, sob a hipótese de que o agrupamento de todas, dê o resultado esperado. Tardif vai além, ao constatar que a formação do professor se dá efetivamente nas práticas escolares:

[...] os cursos de formação para o magistério são globalmente idealizados segundo um modelo aplicacionista do conhecimento [...] segundo uma lógica disciplinar e não segundo uma lógica profissional centrada no estudo das tarefas e realidades do trabalho dos professores. (TARDIF, 2000, p. 18-19).

O PIBID criado em 2007 sob a coordenação da Capes/ MEC, insere-se como uma alternativa promissora de formação de professores, na medida em que tem como objetivo aproximar a Educação Básica e as Licenciaturas, superando aquela formação tecnicista. Ao longo desse curto período de existência, o PIBID "vem se transformando de programa de iniciação à docência em uma política pública de formação de professor" (SILVA; NUNES, 
2016). Na edição de 2019, passou a ser ofertado juntamente com o Programa de Residência Pedagógica (PRP), este equivalente à prática pedagógica dos estágios supervisionados, e por isso, adequado para os licenciandos que cursaram mais da metade da licenciatura. Assim, os candidatos a participantes do PIBID são os licenciandos das primeiras fases, o que traz um novo desafio: Como alguém pode iniciar-se na docência, sem conhecer razoavelmente a Matemática, os princípios básicos de aprendizagem e da Didática?

A alternativa do grupo proponente do PIBID/UFFS/Matemática para enfrentar tal desafio, foi superar a formação tecnicista - já que isso repetiria a graduação - e a estrutura desconectada dos saberes da licenciatura, entendendo que a formação profissional do professor é temporal e pode ser construída a partir da prática pedagógica, devidamente iluminada pelos conhecimentos teóricos, pela análise crítica tanto da teoria como da prática, em um ambiente de interação entre coordenadores, supervisores e pibidianos. Esses entendimentos são expostos na seção $D a$ teoria à prática ou da prática à teoria? Na seção $A$ unidade entre teoria e prática, na prática são descritas as atividades de planejamento, a apresentação e analisadas as microaulas realizadas pelo núcleo ${ }^{3}$, na perspectiva de realizar a formação profissional pela racionalização da prática pedagógica, elaborando coletivamente os saberes experienciais mediante a vivência, mas também com o uso dos saberes disciplinares, curriculares e profissionais.

A elaboração cooperativa dos saberes experienciais, o ambiente cultural desenvolvido pelo núcleo nessas primeiras experiências e a necessária unidade entre prática e teoria foram apon-

\footnotetext{
${ }^{3}$ A expressão núcleo é usada nesse artigo para referir-se aos participantes do Núcleo de Matemática do PIBID/UFFS: 24 os alunos pibidianos do Curso de Licenciatura em Matemática da UFFS/Chapecó, coordenador e vice-coordenador do Núcleo e três supervisoras, professoras de Escolas Públicas do município de Chapecó/SC.
} 
tados como os principais ganhos no processo de construção da identidade do professor.

\section{DA TEORIA À PRÁTICA OU DA PRÁTICA À TEORIA?}

A dicotomia entre prática e teoria na educação é apontada por diversos autores, como Freire (1978), Damasceno (1987), Pimenta (1999), Tardif (2000), Souza (2001). O compromisso de ensinar uma carga razoável de conteúdos em condições limitadas, com salas sem ar condicionado, alunos com diferentes interesses, sem laboratórios, sem materiais didáticos, poucos livros e aulas de 50 ou 100 minutos, tende a esgotar as possibilidades de reflexão sobre a prática pedagógica. Nesse contexto de adversidades são forjados os saberes experienciais.

Esses saberes são adquiridos ao longo da experiência de vida, tanto como aluno quanto como professor - portanto são temporais. É comum professores constatarem que trazem expressões, posturas, crenças, bibliografias e mesmo enfoques de conteúdo herdadas de seus mestres da escola ou da graduação. Nos primeiros anos de prática nas escolas, o professor se debate entre o domínio do conteúdo (momento no qual os livros didáticos apresentam a matemática escolar, diferente da matemática estudada na universidade), os problemas de ensino e aprendizagem (como proceder para ser entendido e que os alunos aprendam?) e os problemas de relacionamento com as turmas (controle, disciplina, respeito). $\mathrm{O}$ enfrentamento de toda essa realidade ocorre de forma intuitiva, por observação dos colegas, sem uma racionalização sobre o acontecido e com um uso mínimo dos saberes profissionais aprendidos na universidade. Como se refere Tardif,

[...] os primeiros anos de prática profissional são decisivos na aquisição do sentimento de competência e no estabelecimento das rotinas de trabalho, ou seja, na 
estruturação da prática profissional. Ainda hoje, a maioria dos professores aprende a trabalhar na prática, às apalpadelas, por tentativa e erro. (TARDIF, 2000, p. 14).

Por outro lado, os saberes curriculares e profissionais são ensinados nas licenciaturas aprofundando questões teóricas específicas desses saberes, o que é fundamental para a formação do professor como um intelectual. Nos saberes curriculares, ocorre a aplicação daqueles saberes para o desenvolvimento e prática de métodos e técnicas de ensino. Tem-se assim, métodos e técnicas orientados com as finalidades políticas da educação como formadora dos novos cidadãos para a sociedade e gerados de acordo com as concepções científicas de aprendizagem. Essa elaboração teórica dos saberes curriculares não considera as condições de aplicação em espaços reais nas escolas, nem todo o saber experiencial decorrente da vivência de professores veteranos, evidenciando a dissociação entre saberes profissionais (teóricos) e experienciais (prática). Assim, os primeiros não chegam ao seu objetivo - a transformação da escola - e os últimos se restringem a ações sem pensar e por isso, se consolida como crenças, empobrecendo a qualidade da educação. Para Souza

Ao isolar a teoria da prática ou a prática da teoria, o homem é destituído de sua capacidade de agir de forma consciente, é impossibilitado de compreender os condicionamentos que o determinam, é privado da possibilidade de (re)construir sua realidade. (SOUZA, 2001, p. 7)

O rompimento da dicotomia entre teoria e prática não tem sido uma tarefa fácil devido à orientação dos trabalhos das universidades e das escolas. As primeiras orientadas a produzir conhecimento e as segundas a efetivar o trabalho educativo. A concepção dialética 
[...] apresenta-se como um caminho promissor. Esta abordagem considera que o conhecimento verdadeiro decorre da atividade prática orientada por uma teoria crítica. A partir da visão dialética a relação teoria prática é repensada e redimensionada numa nova perspectiva à unidade teoriaprática, marcada pela autonomia e a dependência recíproca de ambas. (DAMASCENO, 1987, p. 38).

O PIBID se coloca como uma oportunidade de superação daquela dicotomia, pela condição de aproximar os quatro tipos de saberes elencados por Tardif e possibilitar os espaços e tempos de elaboração da crítica a todos eles pela vivência entre professores das escolas, das universidades e universitários: a elaboração dos saberes do professor mediante a prática e a crítica produzida coletivamente pelos sujeitos.

O desafio de propiciar uma iniciação à docência a quem pouco conhece dos saberes disciplinares a ensinar, levou a coordenação do núcleo a propor estudos iniciais sobre a natureza do conhecimento matemático: o que é a Matemática? Como ela é feita? Quem pode fazê-la? Que importância ela tem para a sociedade atual? O livro A Experiência Matemática de Davis e Hersh (1985) com sua linguagem simples e objetiva foi uma das fontes utilizadas para responder a essas questões. Entender a Matemática como um conhecimento dedutivo é entender a sua estrutura formal, constituída de axiomas que são a base para a construção das teorias matemáticas. Desse modelo, depreende-se que fazer Matemática é argumentar sobre a verdade de proposições, mas não é apenas isso. A criação de proposições depende de observações de casos particulares, de verificação de regularidades, de testes empíricos, enfim, de raciocínio indutivo e de uma linguagem simbólica para expressá-lo. O processo dedutivo (demonstração), portanto, é posterior ao indutivo (percepção e criação).

Essas concepções (dedutiva e indutiva) foram reforçadas com a leitura de dois artigos: Carvalho e Ripoll (2013) e Nunes e 
Almouloud (2013). Ambos enfatizam a possibilidade de praticar o pensamento matemático na Escola Básica, com adaptações de linguagem e rigor, em uma linha de argumentação matemática com diferentes linguagens, convergindo para a linguagem técnica simbólica.

As aplicações da Matemática nas Ciências também foram reconhecidas como um valor social, uma vez que toda a tecnologia do mundo moderno - a qual interfere significativamente na vida das pessoas - tem como conhecimento básico a linguagem e os conceitos matemáticos, sendo esse um argumento para intensificar o ensino de Matemática nas escolas.

A leitura do livro Psicologia da Educação Matemática: uma introdução (FALCÃO, 2008) foi proposta para entender como o ser humano aprende os conceitos matemáticos, questão essa importante para elaborar atividades de ensino. Os fundamentos das correntes comportamentalista e cognitivista foram estudados e discutidos no núcleo, de forma relacionada com procedimentos didáticos, como o treinamento de algoritmos, a prática de exercícios, a memorização de fórmulas e a ação do aluno na elaboração de sentidos e significados.

Com uma noção do que ensinar e de como o ser humano aprende, foram propostos estudos sobre metodologia de ensino, particularmente sobre aulas expositivas e aulas ativas, associando-os às teorias de aprendizagem e à natureza do conhecimento e do pensamento matemático. O vídeo Didática para a aula expositiva (FACULDADE DE FILOSOFIA, CIÊNCIAS E LETRAS DE CARUARU, 2019) e o artigo Situações em que a aula expositiva ganha eficácia (MADEIRA, 2015) contribuíram para a análise dos tipos de aulas expositivas assim como a descrição de aulas com modelagem deram uma noção de aulas ativas.

A experiência dessas primeiras atividades de leituras e discussões, porém, não pode ser avaliada apenas por relatórios de leitura ou pela retenção de conteúdos. Tão importante quanto o produto, nesse caso, foi o modo de trabalho, a exposição das 
experiências dos sujeitos nas discussões, o ambiente de diálogo, o enfrentamento das dificuldades, o respeito ao modo de pensar do outro e a consciência de estar em um processo de transformação das próprias ideias. Entende-se assim, que a teoria dos textos (saberes profissionais) foi entendida na sua essência via leitura, mas principalmente associada a situações de aulas (saberes curriculares), em um processo de interação entre sujeitos com diferentes formações, o que propiciou uma racionalização dos fatos pedagógicos, na direção de uma unidade entre teoria e prática. A descrição das discussões das microaulas na seção seguinte reforça essa constatação.

\section{A UNIDADE ENTRE TEORIA E PRÁTICA, NA PRÁTICA}

Para promover o acesso aos saberes disciplinares, profissionais, curriculares e experienciais, todos em conjunto, foram propostas atividades de planejamento e apresentação de microaulas, com diferentes focos de análise, como oficinas pedagógicas, de discussão e análise no núcleo: 1) Aulas iniciais: que matemática é ensinada; 2) Aulas expositivas; e 3 ) Aulas ativas.

Nas Aulas iniciais, os pibidianos, em duplas, escolheram um conteúdo de Matemática da Educação Básica, estudaram os conceitos e propriedades envolvidos, planejaram e ministraram uma microaula de 20 minutos para o núcleo. Não houve nenhuma indicação quanto ao tipo de aula, se diretiva, ativa, palestra, investigação ou participativa. Tampouco se recomendou o planejamento de processos indutivos, dedutivos ou de aplicação em problemas reais. Apenas uma aula a ser construída com base na cultura pedagógica adquirida como alunos, que se constituiu na primeira experiência de oficina pedagógica: um espaço-tempo de criação, diálogo, reflexão e crítica sobre os atos de ensinar e aprender em sala de aula. 
O tipo de aula dominante nas apresentações foi a aula expositiva, com descrição de textos de livros didáticos. A preocupação com o domínio do conteúdo foi evidente, confirmando a expectativa de que os alunos deveriam aprender Matemática antes de ensinar. A prática de estudar para lecionar é comum tanto para professores iniciantes como para veteranos, ao lecionar alguns conteúdos pela primeira vez, mostrando a necessidade de uma boa formação na licenciatura. É senso comum que o professor melhora seu conhecimento sobre o conteúdo na medida em que prepara e ministra suas aulas, tanto pela repetição, quanto pela percepção de novos pontos de vista, de perguntas dos alunos, de novas leituras a cada vez que planeja o mesmo conteúdo. Pode-se dizer que o professor aprende para ensinar, mas que também, ao ensinar, aprende.

Observou-se nessa primeira experiência, uma natural ansiedade de falar em público, para os colegas e professores, manifestada no modo de falar, gesticular e expor as ideias da aula. Falar em público é uma habilidade que se aperfeiçoa com a experiência e com o tempo. Nesse sentido, o ambiente da oficina foi construindo-se aos poucos, na medida em que os agentes foram entendendo o espaço como experimental, onde o certo e o errado são relativos.

O uso do quadro e de eventuais materiais didáticos é também uma habilidade aprendida com o tempo. $\mathrm{O}$ tamanho das letras, a organização do texto, a clareza dos desenhos e ideias, para além do aspecto estético, podem ajudar o aluno a compreender a exposição do professor, evitando a solicitação de esclarecimentos.

Além dos aspectos didáticos das aulas, foram identificadas, nos procedimentos de ensino, algumas das ideias discutidas nos textos:

- as afirmações matemáticas sem justificativas, como os algoritmos operatórios ensinados como regras simplesmente memorizadas, foram questionadas porque não refletiam o modo de pensar matematicamente; 
- os processos de abstração: expressão de observações do real (geralmente material concreto) em linguagem natural, desenhos ou simbólica;

- os processos indutivos e generalizações: análise de resultados particulares, indução de proposições e generalização sem demonstrar;

- as argumentações: tentativas de argumentação com linguagem natural, pictórica ou formal (processos dedutivos);

- o aperfeiçoamento de conceitos: evolução na construção de conceitos ao realizar diferentes atividades;

- a contextualização da Matemática: situações de aplicação do conhecimento para resolução de problemas reais.

Assim, procurou-se iluminar a prática pedagógica com a epistemologia da Matemática, mostrando que - mesmo sem a consciência do professor - uma ação de ensino carrega consigo uma concepção de Matemática seja ela dedutiva, indutiva, pura ou aplicada. Observou-se que o exercício teoria-aulas-análise-reelaboração contribui para a formação do professor, não de forma mecânica, na qual se mostra o como se faz, mas de forma vivenciada e elaborada coletivamente, como um processo de construção da identidade profissional de cada um, pretensiosamente, fazendo a unidade entre a teoria e a prática.

Entendendo a Didática como a área da educação em que são desenvolvidas e analisadas as propriedades e finalidades das técnicas e dos métodos de ensino, pode-se dizer que é o componente curricular natural dos saberes curriculares. No modelo tecnicista (aplicacionista para Tardif), esses saberes deveriam ser aplicados nos estágios e na prática pedagógica escolar. No entanto, isso não ocorre de modo geral. É comum os professores desenvolverem um saber experiencial na própria prática, com o dia a dia da sala de aula, observação do trabalho de colegas, que substitui os saberes curriculares teóricos universitários. É uma forma de aprender eminentemente pragmática, na qual a reflexão e a crítica perdem espaço à improvisação e à tomada de decisões intuitivas. 
A aula expositiva é uma das técnicas de ensino mais utilizadas para ensinar Matemática, tanto na Escola Básica como na universidade. Talvez não pela eficiência e qualidade do ensino produzido, mas pela adequação em termos de praticidade, considerando as condições de trabalho do professor, no que se refere ao tempo disponível para ensinar todo o programa de conteúdos indicados nos planos de ensino. Os pibidianos foram provocados a elaborar o planejamento e ministrar uma microaula expositiva sobre um conteúdo de Matemática da Escola Básica.

$\mathrm{Na}$ aula expositiva clássica, o professor expõe, o aluno copia e repete em atividades como exercícios e provas. A participação do aluno se restringe a pedidos de esclarecimentos e a prestar atenção na fala e na escrita do professor. É pressuposto que os alunos sejam capazes de entender o conteúdo, memorizar e aplicar quando solicitados.

Variações nesse tipo de aula podem entender o professor como um palestrante animador que dialoga (aula expositiva dialogada), fazendo perguntas como forma de chamar atenção, provocar a participação e perceber o ponto de vista dos alunos. A manipulação de materiais didáticos (figuras, sólidos geométricos, gráficos, objetos) pelo professor pode dinamizar um pouco mais, permitindo que os alunos visualizem, mesmo que não manipulem os objetos. O uso de equipamentos multimídia pode ser um apoio como recursos de animação, cálculos rápidos, cores e gráficos dinâmicos, que reforçam a exposição, mas mantêm os alunos na qualidade de espectadores.

Mesmo com a dinamização do diálogo, a tendência da aula expositiva é de recorrer à memorização de regras, teoremas e processos - sejam eles conceituais ou simplesmente de execução algorítmica, o que a aproxima das concepções comportamentalistas de aprendizagem. Uma demonstração matemática executada pelo professor, sem a atribuição de significados pelo aluno, tende a ser um objeto matemático a ser decorado, ao invés de com- 
preendido. $\mathrm{O}$ uso de propriedades, ou o treinamento da execução de algoritmos sem domínio do sentido das operações, leva a erros ingênuos, pois o significado dos símbolos para os alunos não corresponde aos significados pressupostos na teoria. A redução dessa diferença entre os significados pode ser trabalhada com atividades de comunicação entre professor e aluno, de tal forma que as concepções equivocadas sejam identificadas e reelaboradas.

Além disso, questiona-se se a aula expositiva tende a formar alunos passivos - aqueles que esperam ordens e tarefas que devem desempenhar - com pouca iniciativa de criação e pensamento matemático próprio.

O estudo da aula ativa foi iniciado com um seminário, no qual foram evidenciados os seguintes pressupostos:

- A aprendizagem é um processo resultante das interações entre o indivíduo, o meio e os sujeitos. Essas interações estão presentes, de certo modo também na aula expositiva, pois há uma interação entre os sujeitos e o meio. Porém, nesse tipo de aula, as interações são restritas à atuação condutiva do professor e mesmo que ocorra a aprendizagem, entende-se que ela é bastante limitada. Assim, se os alunos interagirem entre si e com o meio de forma mais livre, é possível que outros tipos de situações de aprendizagem aconteçam.

- O aluno é ativo no processo de elaboração do conhecimento. Em contraponto com a passividade, submissão e obediência da aula expositiva, na aula ativa o aluno é desafiado a agir por conta própria, tomar iniciativa, desenvolver a sua forma de pensar, expor o seu pensamento, defendê-lo, modificá-lo pela interação com os colegas e professores.

- O professor é mediador, problematizador e incentivador do processo de aprendizagem. $\mathrm{Na}$ aula ativa o professor não tem a função de apresentar o conteúdo necessariamente, 
porém, isso não significa que a elaboração do conhecimento fique apenas a cargo dos alunos. Isso levaria muito tempo e seria inviável em escolas reais, onde o período das aulas é limitado a no máximo 100 minutos. A função do professor é acompanhar as ações dos alunos fazendo perguntas esclarecedoras, indicando possibilidades, questionando conclusões equivocadas, enfim, mediando a elaboração do conhecimento para que ela aconteça, sem, contudo, fazê-la por eles.

- O processo de aprendizagem visa a desenvolver a curiosidade, a criatividade, o senso crítico e a autonomia. Admitindo a liberdade de pensamento, o relacionamento social e a expressão dos alunos é de se esperar o desenvolvimento de interesses por estudos sistemáticos, pela elaboração de opiniões próprias, pelo debate de ideias e pela busca de espaço no grupo escolar e social.

Um debate especial ocorreu no seminário sobre a aula ativa, ao considerar as dificuldades de realização nas escolas públicas, visto que necessitariam de muito tempo, impossibilitando ensinar todo conteúdo proposto para cada ano. Além disso, que garantias pode-se ter sobre a qualidade da elaboração do conhecimento efetuada pelos alunos? Tais questões foram discutidas analisando o esquema da Figura 1. De fato, o tempo de elaboração do conhecimento e a duração das aulas na escola formal ${ }^{4}$ podem não ser compatíveis. A realização de tarefas em casa pode ajudar nesse sentido. Porém, a mediação do professor como sistematizador dos estudos é que pode garantir a elaboração do conhecimento. A sistematização ocorre na orientação dos alunos (geralmente

\footnotetext{
${ }^{4}$ Neste texto, usamos a expressão escola formal referindo-nos à escola clássica, com horários, períodos de aula para cada disciplina, conteúdos programáticos ordenados, tal como são as escolas públicas em geral. Existem outros tipos de escolas com propostas mais flexíveis com relação a horários, espaços e ordenação de conteúdos, como as escolas experimentais.
} 
atuando em grupos), na socialização das elaborações de cada grupo para a turma toda e nas atividades complementares (questões e exercícios), como sugere a Figura 1. É na socialização que ocorrem as sínteses, os aperfeiçoamentos, os registros em linguagem natural e matemática, a estruturação dos conceitos e proposições. Dessa maneira, o conhecimento é elaborado coletivamente por alunos e professor. As atividades complementares (exercícios de revisão) cumprem a função de tornar o conteúdo mais claro, mais familiar pelo uso em aplicações diversas e desenvolvimento de habilidades com a linguagem e os algoritmos.

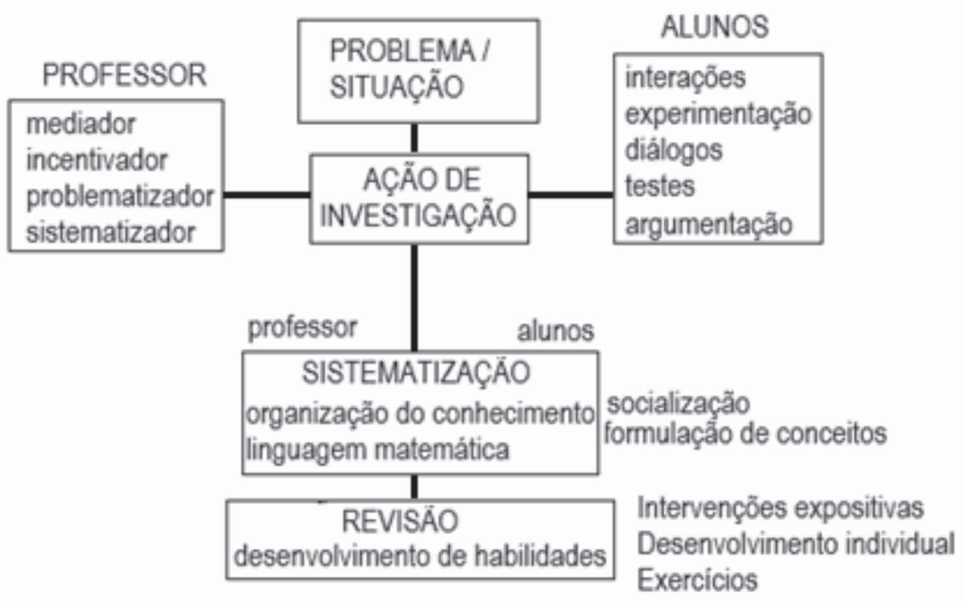

Figura 1 - Esquema de uma aula ativa Fonte: Elaborada pelos autores

A aula ativa não é muito conhecida nas escolas, como é a aula expositiva. É comum alunos chegarem no Ensino Superior sem ter experienciado esse tipo de metodologia. Por isso, os pibidianos vivenciaram uma aula de modelagem, com o seguinte problema: determinar um método para fabricar uma Rosca 
Transportadora Helicoidal ${ }^{5}$ ? Cinco grupos de alunos investigaram o problema e o resolveram coletivamente, com a mediação dos professores, em cerca de 70 minutos. As soluções foram obtidas combinando a construção em papel de cilindros e helicoides a partir de uma coroa circular (fase de investigação com material concreto), seguida da abstração do problema com a escolha das variáveis principais e o estabelecimento das relações entre elas (fase da investigação de modelos matemáticos). A Figura 2 mostra a construção de um dos grupos. As atividades de sistematização propostas retomaram os conceitos de raio, coroa circular, número (p), circunferência e o Teorema de Pitágoras envolvidos na solução, extrapolando o sentido de aplicação com a provocação de investigações matemáticas ${ }^{6}$ (fase de sistematização).

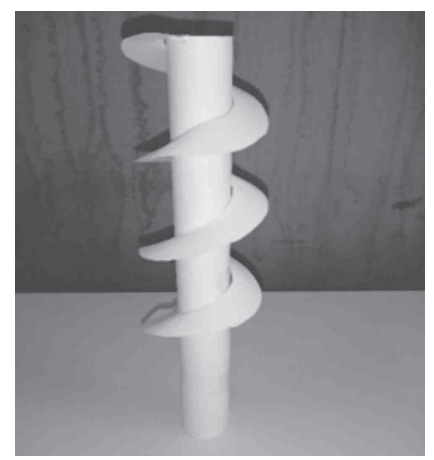

Figura 2 - Modelo físico da Rosca Transportadora Helicoidal Fonte: Elaborada pelos aurores

\footnotetext{
5 A Rosca Transportadora Helicoidal é conhecida também por Chupim, Elevador e Rosca Sem-Fim. Arquimedes de Siracusa (287 a.C. a 212 a.C) já utilizava a rosca dentro de um cilindro para elevar água, girando-a com tração animal. Atualmente, a rosca tem várias utilidades: perfurar o solo, elevar cereais, areia, água, dentre outras.

${ }^{6}$ Foram investigadas as questões: 1 ) por que $C=2(\pi) r$ ? onde $C$ é a circunferência e $r$ é o raio; e 2) se um triângulo é retângulo, então $a^{2}=b^{2}+c^{2}$, onde $a$ é o lado maior e $b$ e $c$ os menores. Como fica essa relação quando o triângulo não é retângulo?
} 
Ao se colocarem na posição de alunos, os pibidianos vivenciaram as dificuldades e as angústias de decidir o que fazer em um processo de investigação, de buscar conhecimentos para resolver problemas, de defender seus pontos de vista, de escutar o outro e de produzir acordos. Na análise da atividade, discutiram o problema do tempo de execução, a sistematização e as funções do professor como mediador. Visando a desenvolver uma prática mais consistente, os pibidianos foram convidados a produzir aulas ativas a serem aplicadas e analisadas pelo núcleo, em modo de oficina, semelhante efetuado nas aulas expositivas.

Os seminários têm cumprido uma função de significação da teoria, na medida em que se associam pelo diálogo, concepções sobre a natureza da Matemática ou sobre a aprendizagem, a tratamentos de conteúdos e procedimentos de ensino. Entende-se que dessa forma, o conhecimento científico da formação acadêmica contribua para entender os fenômenos de sala de aula e consequentemente, qualifique as decisões e ações da prática pedagógica.

As oficinas, por sua vez, são práticas pedagógicas em que os pibidianos vivenciam as dificuldades e os prazeres de ensinar, mesmo que em simulações com os colegas. Não se trata de aplicações mecânicas da teoria acadêmica, mas de análise coletiva das práticas com elementos teórico-científicos, para uma formação racional gradual, construída socialmente a cada experiência.

\section{CONSIDERAÇÕES FINAIS}

O desafio de iniciar na docência, alunos com poucos conhecimentos de Educação e Matemática permanece na sequência do programa, porém com algumas questões mais esclarecidas com o que foi vivenciado até o momento:

- A superação do modelo tecnicista por um modelo de elaboração coletiva e cooperativa evita a artificialidade do 
aprender para aplicar, e leva os pibidianos a lerem o ambiente escolar real tal como ele é. Essa mudança de postura não é um jogo de palavras teórico, mas um método de pesquisa e trabalho que considera, observa e analisa o fenômeno pedagógico (escola/aula/professor/aluno/sociedade) para depois planejar a vivência profissional. Não se trata, assim, de uma intervenção do professor na escola, mas de uma formação do professor na escola.

- O ambiente construído pelo núcleo nessas primeiras experiências mostrou-se, além de agradável, efetivo. As interações entre os professores das escolas e da universidade com os pibidianos evidenciaram as crenças, as experiências e as conviç̧ões de cada um, expressas nos debates, de maneira compromissada com o estudo crítico e profundo, na busca da elaboração das concepções individuais, superando a doutrinação em nome de uma ou outra tendência pedagógica.

- Ficaram evidentes as noções de que os saberes curriculares e os experienciais necessitam de elaboração conjunta. A prática profissional na escola é fortemente limitada pela pressão da atitude, da urgência de providências, das restrições de recursos, resultados esperados e quase ausência de reflexão sobre ela mesma. O parar e pensar, por essa razão, torna-se necessário para ver o que pode ser feito de forma mais eficaz, se o desejo for uma educação matemática mais conceitual. Nesse sentido, a teoria é necessária, desde que voltada para a prática e suas transformações.

O trabalho realizado até o momento é uma construção coletiva da identidade de professor de cada membro do núcleo, não somente dos pibidianos, pois a "identidade não é um dado imutável. Nem externo, que possa ser adquirido. Mas é um processo de construção do sujeito historicamente situado." (PIMENTA, 1999, p. 18). 


\section{REFERÊNCIAS}

CARVALHO, Sandro Azevedo; RIPOLL, Cydara Cavedon. O pensamento matemático na Escola Básica. Zetetiké - FE/Unicamp, São Paulo, v. 21, n. 40, p. 149-161, jul./dez. 2013.

DAMASCENO, Maria Nobre. A relação teoria: prática na ação docente. Revista Educação em Debate, Fortaleza, Ano 10, n. 13, p. 40-51, 1987.

DAVIS, Phipip J.; HERSH, Reuben. A experiência matemática. Rio de Janeiro: F. Alves, 1985.

FACULDADE DE FILOSOFIA, CIÊNCIAS E LETRAS DE CARUARU (FAFICA). Didática para a sala de aula - Aula expositiva. [2019]. Disponível em: https://www.youtube.com/watch?v=RqEXZ9sBAY4. Acesso em: 2 abr. 2019.

FALCÃO, Jorge Tarcísio da R. Psicologia da Educação Matemática: uma introdução. Belo Horizonte: Autêntica, 2008.

FREIRE, Paulo. A alfabetização de adultos: é um que fazer neutro? Educação e Sociedade, São Paulo, v. 1, p. 64-70, set. 1978.

MADEIRA, Miguel Carlos. Situações em que a aula expositiva ganha eficácia. In: EDUCERE, Congresso Nacional de Educação, 12., vol. 1., 2015, Curitiba. Anais [...] Curitiba: PUCPR, 2015. p. 36.015-36.029.

NUNES, José Messildo Viana; ALMOULOUD, Saddo Ag. Argumentação no ensino da matemática: perspectiva metodológica. REMATEC, Natal, RN, Ano 8, n. 13, p. 145-169, 2013.

PIMENTA, Selma Garrido. Formação de professores: identidade e saberes da docência. In: PIMENTA, Selma Garrido (org.). Saberes pedagógicos e atividade docente. São Paulo: Cortez, 1999. p. 15-34.

SILVA, Solange Mendes da; NUNES, Claudio Pinto. O PIBID como política pública de formação de professores. Educação em Debate, Fortaleza, ano 38, n. 72, p. 89-103, 2016. 
SOUZA, Nadia Aparecida de. A relação teoria-prática na formação do educador. Semina - Ciências Sociais e Humanas, Londrina, v. 22, p. 5-12, 2001.

TARDIF, Maurice. Saberes docentes e formação profissional.

Petrópolis: Vozes, 2008.

TARDIF, Maurice. Saberes profissionais dos professores e conhecimentos universitários: elementos para uma epistemologia da prática profissional dos professores e suas consequências em relação à formação para o magistério. Revista Brasileira de Educação, Rio de Janeiro, n. 13, p. 5-24, jan./fev./mar./abr. 2000.

UNIVERSIDADE FEDERAL DA FRONTEIIRA SUL (UFFS). PIBID Programa Institucional de Bolsa de Iniciação à Docência. 2018. Não publicado. 